\title{
Na simplicidade a complexidade de um cuidar: a atuação da benzedeira na atenção à saúde da criança
}

\section{I ${ }^{1}$ Rafael Eduardo Gurgel de Medeiros, ${ }^{2}$ Ellany Gurgel Cosme do Nascimento, \\ ${ }^{3}$ Gabriele Maria Dantas Diniz, ${ }^{4}$ João Carlos Alchieri I}

Resumo: Falar em cultura e saúde é adentrar questôes como religião e espiritualidade, terapias não oficializadas que perpassam o misticismo dessas questões, e que, apesar de não possuírem a comprovação técnico-científica exigida pelo atual modelo em saúde hegemônico, são um saber que se mantém vivo durante toda a história da humanidade e que se perpetua até os dias de hoje. O trabalho objetivou analisar a percepção das benzedeiras sobre o cuidado à saúde da criança, enfocando a prática da benzeção no município de Caraúbas. Tratase de estudo qualitativo de caráter exploratório, realizado por meio de entrevista semiestruturada, com amostra composta por 16 benzedeiras residentes no setor urbano do município de Caraúbas-RN.

Evidencia-se um cuidado baseado em aspectos que envolvem a afetividade, observando-se que as benzedeiras seguem um perfil muito semelhante no tocante às crenças e na utilização do ritual de cura. As benzedeiras apresentam disposição em articular arte e ciência, visualizado pelo encaminhamento e reconhecimento da importância do sistema oficial em saúde. Configura-se um espaço para a Estratégia Saúde da Família realizar parcerias que incentivem o uso concomitante entre essa modalidade terapêutica e o sistema oficial, contribuindo assim para melhoria da assistência.

\author{
1 Enfermeiro; Secretaria \\ Municipal de Saúde de \\ Caraúbas/RN. Endereço \\ eletrônico: rafaelgurgel1@ \\ hotmail.com \\ 2 Enfermeira; docente do \\ Curso de Graduação em \\ Enfermagem no CAMEAM/ \\ UERN e doutorando do Curso \\ de Pós-Graduação em Ciências \\ da Saúde/UFRN. Endereço \\ eletrônico: ellanygurgel@ \\ hotmail.com \\ ${ }^{3}$ Enfermeira; mestranda do \\ Curso de Pós-Graduação \\ em Saúde e Sociedade/ \\ UERN. Endereço eletrônico: \\ gabrieledinizz@hotmail.com \\ ${ }^{4}$ Psicólogo; docente do Curso \\ de Graduação em Psicologia \\ e Pós-Graduação em Ciências \\ da Saúde/UFRN. Endereço \\ eletrônico: jcalchieri@gmail. \\ com
}

Recebido em: 31/07/2012 Aprovado em: 20/12/2013 
São as questôes que envolvem religião e espiritualidade que vão sustentar as práticas alternativas ligadas à fé, entre elas a benzeção. $\mathrm{O}$ profissional em saúde pode reconhecer essa ação como importante determinante nas formas de consumo em saúde, cujo impacto recai não só sobre um ser individual, ou como se costuma pensar, em pequenos grupos populacionais, mas sobre toda a população, pois todo indivíduo é dotado de crenças, hábitos e costumes de uma rede cultural própria. A prática profissional e o cuidado devem ser pensados reconhecendo que o indivíduo não se resume aos aspectos fisiológicos. É possível reconhecer e identificar as implicações dessa modalidade terapêutica no processo saúde-doença, procurando ampliar o foco do cuidado para além da dimensão biológica do indivíduo, considerando as singularidades e particularidades, em um diálogo permanente entre os diferentes modos do cuidar.

Trabalhar a saúde da criança dentro da discussão de Terapias Complementares e Alternativas, em especial a benzeção, surgiu pela preocupação com esse público, pois o uso indevido dessas ações pode provocar danos irreversíveis na qualidade de vida desses usuários. Soma-se a essa questão o fato de ser um público aparentemente com mais facilidade de adquirir patologias que normalmente são vistas como sobrenaturais pelos consumidores da benzeção.

\section{Método}

Pesquisa qualitativa de caráter exploratório, realizada na cidade de Caraúbas, interior do estado do Rio Grande do Norte, Brasil. A amostra foi composta por 16 das 30 benzedeiras atualmente residentes no setor urbano do município de Caraúbas, que exerçam ou que já tenham exercido essa prática. $\mathrm{Na}$ tentativa de favorecer a obtenção do maior número de entrevistados, foi eleita como estratégia de obtenção de dados a entrevista em domicílio. Além de possibilitar maior adesão, esta é um espaço privilegiado para diálogo e construção de saberes, uma vez que capta os achados no próprio ambiente do entrevistado, deixando-o mais à vontade para expressar suas opiniōes. Uma vez obtidos os dados, foi utilizada como metodologia a análise do discurso, que busca compreender o modo de funcionamento, as formas de produção social e os princípios que regem a organização do sentido (MINAYO, 2000). Como medida de garantir a ética na pesquisa, o projeto foi submetido à aprovação do 
Comitê de Ética em Pesquisa (CEP), da Universidade do Rio Grande do Norte (UERN), protocolo 090/2012, CAAE 0085.0.428.000-10.

$\mathrm{Na}$ análise das falas, podemos observar a atual utilização dessas práticas mesmo diante da expansão dos modelos tradicionais de assistência, a constante credibilidade das benzedeiras, os condicionantes que influenciam a utilização (ou não) dessas práticas na dinâmica social em saúde e a visão das entrevistadas acerca do cuidado a saúde da criança. Para melhor discutir as falas, estas foram organizadas em três categorias: "o sobrenatural e o ritual", na qual iremos discutir a simbologia dessa prática como importante fator para sua perpetuação; "o humano e o cuidado", analisando como é desenvolvido o cuidado nos processos de cura dessa prática; e "a reza e o erudito", abordando como ocorre a relação entre esses dois saberes dentro e fora dos espaços de benzeção. Deve-se esclarecer, no entanto, que em muitos casos essas variáveis se entrelaçam, sendo divididas apenas para fins de discussão dos achados.

\section{Análise e discussão}

\section{Perfil dos entrevistados}

Observou-se que o perfil desses profissionais é uma importante variável na procura por esse serviço. Dos 16 entrevistados, 15 são do sexo feminino e apenas um do sexo masculino. Como predominam mulheres, optamos pela utilização de palavras que remetam a esse sexo, para tratar as pessoas que praticam a benzeção. Algumas características em comum foram encontradas nos participantes, como mulheres idosas, na faixa etária em torno de 73 anos, tendo a mais nova 50 anos, e a mais velha 91 anos; baixa renda; e pouca escolaridade. Todas se dizem católicas, embora já tenham tido experiências em outras religiôes, principalmente a espírita. Quatro das entrevistadas relataram que começaram a benzer depois que foram introduzidas nessa doutrina; pôde-se observar que após o abandono, essas pessoas ainda apresentam traços simbólicos que emergem de ambas as religiōes.

Foi um dom, eu vivia doente, ai disseram vamos para o centro espírita. Aílá se vai ao centro espírita e eu peguei um espírito e comecei a curar os outros, e o povo achando bonito, e o povo dizendo pra eu rezar, ai fiquei curando até hoje [...] já fui espírita. (B7)

Quanto à profissão, o único homem entrevistado se intitula agricultor. Todas as entrevistadas do sexo feminino se dizem donas de casa, embora já tenham exercido trabalho de agricultoras quando moravam no campo. Essas pessoas vieram para as 
1342 cidades provenientes de sítios e fazendas que faziam parte do município. Foi lá que descobriram seu "dom" e começaram a realizar as primeiras curas.

Nery (2006) comenta que essa prática se desenvolveu sobretudo nos meios rurais, pela escassez de profissionais em saúde. Sabe-se que a benzeção é a expressão de um povo marginalizado pelo sistema de saúde oficial, e por muito tempo esteve entre as poucas alternativas para as pessoas que moravam longe dos grandes centros urbanos ou mesmo não tinham condições de abarcar com os enormes gastos com a saúde.

Algumas das entrevistadas começaram a rezar ainda crianças. Muitas delas aprenderam para garantir a saúde de seus parentes e conhecidos. Seus primeiros clientes foram seus próprios entes, sendo eles as primeiras pessoas a comprovarem seu "poder".

Foi um dom que Deus me deu... Faz 50 anos que eu faço isso, eu aprendi para que ela não morresse (filha), preocupada, porque os filhos nascia e morria de um jeito só, era nascendo e morrendo, nascendo e morrendo. Aí eu me apeguei com a Virgem da Conceição sagrada para ela me ajudasse para fazer a cura da minha filha, para não ver morrer como os outros morreram. E de lá para cá não morreu mais nenhum. Eu fiz por ela, já faz 50 anos que eu faço isso. Eu fiz nela porque antes dela morreram 7. Com medo de minha filha morrer ai eu pedi a Deus, a Jesus e a Virgem sagrada e daí nunca mais morreram nenhuma depois dela já tenho 3. (B5)

Embora seja uma prática utilizada não só pela classe marginalizada, foi por causa dela que a benzeção conseguiu ser perpetuada, e ela é indiscutivelmente sua principal consumidora. Segundo Nery (2006), quem quer que percorra os povoados da zona rural, as pequenas cidades do interior ou mesmo as periferias das grandes cidades vai se deparar, num momento ou outro, com alguns desses nomes que fazem parte de um mundo mágico-religioso, povoado de rezas, crenças, simpatias e benzeções.

Durante a coleta de dados, observou-se predomínio dessas mulheres nos bairros periféricos do município, justamente onde se concentra a maior parte de pessoas com menor poder aquisitivo. As benzedeiras são referência em toda região, atendendo pessoas de várias cidades circunvizinhas. As mais procuradas, conhecidas como as "mais poderosas", afirmam já ter recebido pedidos de pessoas em várias cidades do Brasil, como Recife, Brasília, Rio de Janeiro, São Paulo e Manaus, e até mesmo do exterior, como Estados Unidos, como podemos observar em suas falas. 
Hoje eu tenho muita gente, tenho correspondência por todos os cantos, recebo de São

Paulo, Rio de Janeiro e muitos cantos. Tenho de Brasília [...] se eu disser que até dos EUA, você num acredita. Até de Manaus. (B1)

Seu reconhecimento é tão presente que foram convidadas a participar de entrevistadas em meios de comunicação em massa, não só em nível municipal mas também estadual. Essas mulheres veem a benzeção como algo sério, uma verdadeira profissão que perdura por toda sua vida. Nas falas podemos observar que as crianças são seu principal público. Algumas chegam a se tornar verdadeiras "especialistas" na saúde da criança.

É uma profissão que eu muito gosto, nunca mim reclamei. Passo o dia curando, hoje apareceu 10 criança, daqui a pouco chega um monte de criança para mim rezar. (B1)

Eu rezo mais é em criança. Rezo para mal olhado, dor de cólica e vento caído, agente reza e fica bom. Muita gente me procura, mas é mais criança. (B9)

Hoje essas mulheres são pessoas idosas e mesmo com estado de saúde debilitado continuam a praticar esse modelo terapêutico. Afirmam que pretendem curar enquanto forem vivas, ou enquanto seu estado de saúde permitir. Para elas o trabalho só acaba com a morte ou com a aquisição de uma doença que dificulte ou impeça o trabalho. Elas comentam que já passaram por vários percalços em suas vidas, devido ao aparecimento de uma doença, tendo que parar de realizar a benzeção nesses momentos, mas uma vez que começam a melhorar já retomam seu trabalho. Mesmo aquelas que se dizem muito doentes para rezar, ainda assim se utilizam da reza em momentos de muita precisão, quando a criança necessita de um cuidado imediato e/ou devido a uma patologia grave.

Deixei porque tive uma grande queda, quebrei o braço, fui para Natal. Mas eu quando fiquei boa comecei a rezar novamente, tinha pena, as mães era tudo atrás de mim pra rezar, quando comecei a mexer com o braço, comecei a reza de novo. (B3)

Ate um dia desses a mulher chegou com duas crianças aí eu não pude rezar porque tava muito doente. Aí não rezei mais, deixei de rezar mais "daqui aculá" quando chega um bem doente eu não deixo de rezar [...] porque é ruim para a criança porque descarrega nas crianças, mais uma vez ou outra quando aparece uma criancinha bem doente eu ainda curo. (B13)

É interessante observar que a procura por essas mulheres é significativa, demandando boa parte do seu tempo. Mesmo assim elas exercem seu trabalho sem reclamar, estando disponíveis para qualquer criança que precise de sua ajuda. 
1344 Segundo as informantes, todos os dias aparecem crianças para serem benzidas, o que comprova a boa aderência por parte dos cuidadores.

\section{O sobrenatural e o ritual}

Chama atenção a relação entre o uso dessa terapia e o apelo ao misticismo inerente a essa prática. Essas mulheres se utilizam do sobrenatural e do ritual para a realização de sua contínua reafirmação. Os mesmos elementos que a caracterizam são os mesmos que a determinam. Como afirma Santos, a eficácia da cura se baseia na crença da tríade "curador", "doente" e "coletivo social" no poder místico do processo de cura, produzindo a "eficácia simbólica” na qual curandeiro é visto como elemento condutor para a realização deste.

Como em qualquer ritual, a reza vai necessitar de instrumentos para que se ganhe mais credibilidade. Os objetos utilizados para tal fim são os mais variados e dependem de cada terapeuta, como fala B10: "cada rezador não reza de um jeito só, né?”. Os instrumentos incluem: ramos, água comum, água benta, agulha, linha, pano, roupas, foto, pilão. Mas basicamente eles dizem utilizar apenas o ramo. Em sua fala, uma das entrevistadas ressalta a credibilidade recebida devido à utilização de um ritual diferente do que é costumeiramente realizado pelas demais benzedeiras. Esse ato, segundo ela, aumenta o poder da cura. É o caso, por exemplo, dos galhos de plantas, parte fundamental no ritual, segundo as entrevistadas: "não podem ser qualquer um"; devem ter características peculiares: "a ramos que amargam", "não pode figo, pereiro...”. Entre os mais utilizados estão: vassourinha, laranjeira, pião de São Francisco, arruda, quebra pedra, romã e hortelã.

Não é todo ramo. E eu pego aqueles raminhos de pião de São Francisco, de arruda. Esses de remédio. E quando é para fechar a cura é com água benta pega nas igrejas. (B2)

Raminho verde! Só serve se for de remédio, aquela vassourinha, hortelã, laranjeira... Aqui eu tenho, aqui na minha casa eu tenho. (B5)

Haverkort e Millar, (1994) comentam que existe o costume de manter essas plantas ditas sagradas perto dos locais onde se realiza os rituais, sendo que essa característica é encontrada em outras localidades do mundo. Para ser realizado o ritual, as plantas são colhidas no momento que antecede a benzeção e, como foi visualizado na fala de (B5), as benzedeiras têm por costume plantá-las em suas próprias casas. Em contrapartida, a preferência pelo ramo vai depender de cada 
benzedeira. Apesar da diversidade dos galhos e de sua importância simbólica, para qualquer doença pode ser usado o mesmo ramo, independentemente do tipo de tratamento.

As imagens dos santos católicos constituem outro símbolo bastante utilizado. Seus nomes são continuamente referidos durante as entrevistas. Em muitos casos, inclusive, a benzeção inclui a reza para essas entidades. Apesar de não participarem do ritual em si, as imagens desses santos parecem ser outro ponto forte da benzeção, pois fazem parte da ornamentação do ambiente, que, por conseguinte, contribui com a realização do ritual.

No carregar da oração chamo por ela (a santa) para que ela me ajude todo tempo. (B6)

Eu rezo para o Coração de Jesus e o Divino Pai Eterno e Nossa Senhora da Conceição, e Aparecida [...] dedicado a Nossa Senhora de Fátima que tem as criancinha, Nossa Senhora da Conceição a mãe de Jesus, esses santos eu coloco em minhas orações, pelo menos a salve rainha que é uma oração poderosa... (B5)

Nesse ponto, a imagem acaba servindo não só como instrumento para se adquirir a saúde, mais também um símbolo que reforça a importância de aderir ao tratamento. Para Maciel e Guarim Neto (2006), as benzedeiras representam para seus clientes um canal entre o físico e o extrafísico, o humano e o sagrado; suas recomendações ganham caráter sobrenatural, revogá-las significaria ir contra os próprios agentes divinos. Uma delas chega a ser chamada de santa, indicando o caráter divino a qual ela adquire.

Deus está rezando por mim, não sou eu... (B8)

Tem pessoas que me chama de santa "B2" não é por eu esteja me orgulhando ou esteja me julgando é porque Deus sabe do meu coração e sabe o ato que eu tenho a santa fé e que pra mim eu vivo assim mais pra lá do que pra cá. (B2)

Segundo as entrevistadas, a força da reza não está no ritual, mas na fé, na crença em uma instância maior de cura, que no caso das entrevistadas seria Deus. Para essas mulheres, a fé é o principal fator contribuinte na obtenção da cura. Apenas uma das entrevistadas disse que não haveria necessidade de ter fé na terapeuta; os demais afirmaram que as pessoas teriam que ter fé primeiro em Deus, e depois nelas. A fé também partiria delas, elas precisavam ter fé naquilo que fazem e acima de tudo em Deus. Não é à toa que, em boa parte da entrevista, elas repetiram essa afirmação. 
A benzeção ajuda, mais o que vale é a fé (B1).

Se não tem fé em Deus, como pode? Se não tem fé em Deus aquela cura não vai servi, a fé da pessoa não é na benzedeira não é em Deus, não tendo fé nada serve, sem fé nada serve (B6)

Segundo as entrevistadas, há duas modalidades de benzedeiras: as que receberam de Deus o dom da cura e aquelas que receberam o dom através de outra rezadeira. Isso não faz muita diferença quanto à eficácia da terapia, apenas serve para distinguir a origem do dom e exemplificar como tudo surgiu, como e por que foi delegada àquela mulher a missão de curar. Segundo uma das entrevistadas, o ensino da reza resulta então na perda do dom, que é transferido para o aluno:

Tem o dom que Deus dá e o que é ensinado. (B5)

Tem aquele que tem pelo dom e tem aquele que um ensina, mais não foi Deus que me deu não, eu, foi um curador bem velhinho que me ensinou por causa de um desespero que ele me viu, e ele me viu em um desespero e ele me ensinou pra quando eu tiver com um desespero daqueles [...] (B6)

O dom seria a confirmação da missão delegada por Deus. Algumas benzedeiras afirmam terem tentado fugir dessa missão, mas quando foram constatadas as primeiras curas, logo começaram a ser reconhecidas dentro de sua comunidade. Isso reforça os dizeres de Lévi-Strauss (1991), quando afirmou que um dos aspectos a serem considerados na prática de cura é a crença social no poder da terapia. Podemos observar que apesar de apelar para o sobrenatural, é no real que elas se apoiam. Os benzedores se utilizam dessa terapia porque os sujeitos envolvidos visualizam nela um sentido concreto. Apesar de não sistematizada, é uma prática que raramente se contradiz, daí surge a facilidade com que é aceita pela comunidade.

Não há, portanto o sentimento de dúvida e alienação que costumeiramente se verifica nas intervenções nas terapias convencionais (BORGES; SHIMIZU; PINHO, 2009); ao contrário, há a crença na eficácia de tal procedimento, justificada pela comprovação anterior da cura. B3 inclusive discorre sobre a perpetuação da crença: "Eu já tô rezando nas que eu rezei e ficou bom. E eu já estou rezando nos filhos deles. Faz muito tempo, né?” (B3).

A comprovação social e empírica do método se configura como outro meio que a benzeção utiliza para ser reafirmada cotidianamente. Essas atitudes 
dão à benzeção o alvará para continuar sendo realizada. Diferentemente das propagandas clássicas, o diferencial dessas profissionais é que seus resultados são divulgados pelos próprios consumidores, sem haver esforço por parte delas.

Eu perguntei se ela sabia guarda segredo, eu disse a ela que se ela prometesse não contar o segredo eu tinha o poder de curar ela... Ai eu curei e ela falou que não ia guarda o segredo não. Não podia guarda um segredo desses não e ia ter que contar. (B8)

Pudemos observar nessas falas que a procura pelas benzedeiras é regida pela crença em seus métodos. As palavras e gestos que para nós cientistas significam apenas simbolismo, têm uma conotação diferente para quem está precisando de seus cuidados, ganhando um valor extrafísico que faz das benzeçôes uma terapia de cura distinta das praticadas pela medicina erudita, portando independente da mesma.

\section{O Humano e o Cuidado}

Essa modalidade terapêutica traz uma visão humanística ao processo do cuidar, uma vez que o indivíduo é coparticipante do processo, pois também se torna ativo na busca pela cura, avaliando a eficácia do tratamento, optando pelo uso concomitante de outras terapias e construindo junto às benzedeiras o significado das etapas de adoecimento e cura. Essa visão humanística da prática está ligada ao fato de a benzeção ser vista como um dom.

O dom remete à palavra doação, e essa doação é dada através do trabalho de cura. "Rezar é dom de Deus". (B13). Enquanto um dom dado por Deus, elas afirmam que a benzeção não pode ser vendida. Podemos observar que a benzeção não se confirma como um meio de sobrevivência financeira individual da benzedeira. Podemos verificar nas entrevistas que elas não sobrevivem da benzeção; a reza é um trabalho de caráter voluntário, vista enquanto um dom, algo divino, dado por Deus e por isso se torna um trabalho de doação. Para que a cura seja realmente efetivada, deve ter um caráter de gratuidade e de solidariedade, não havendo, pois, o recebimento de qualquer quantia em dinheiro. A única coisas que elas ganham é reconhecimento e status perante sua comunidade.

Eu na reza não recebo sequer uma prata. Eu não troco o nome de Jesus Cristo e o nome de Nossa Senhora da Conceição. (B2)

Não quero nada não. Nunca recebi nada, eu rezo porque sei rezar e tenho fé, nada vem de ninguém, vou dizer uma coisa, ninguém reza por dinheiro não, perde a força da reza... Precisa ter fé, tendo fé. (B4) 
De todos os determinantes que levam à utilização da benzeção no cuidado a saúde da criança, a humanização na prestação do cuidado é um ponto forte visualizado na pesquisa. Esse trabalho de doação, de caridade, faz com que a prática do cuidado seja embasada em valores humanísticos. Na benzeção, diferentemente das terapias da medicina tradicional, há certeza da gratuidade. Para Archanjo e Leite (2008), as práticas das benzedeiras envolvem atenção e toque, criando um ambiente favorável à cura; além disso, existe a crença no poder simbólico desses atos, acrescida com o fato de a pessoa se sentir cuidada física e emocional.

Algumas chegam a curar em domicílio, em clientes que não podem vir a seu encontro. $\mathrm{O}$ trabalho não se dá apenas naquele momento, a criança vem no mínimo três dias consecutivos para a "cura ser fechada". Foi visualizado que os dias, além de servirem como um momento para a realização da terapia, servem também para saber se a criança está ou não reagindo positivamente à terapia. Nesse período as benzedeiras avaliam se há necessidade de um novo ciclo de reza ou encaminhamento para uma instituição de saúde oficial; na segunda reza é analisada a eficácia do procedimento. Na terceira, se avalia a necessidade de uma possível volta ou uma indicação às práticas convencionais.

Quando a mãe vem com ele a última vez, são três dias ai ela diz, meu filho tá bom, meu filho tá melhor. (B3)

Há um menor distanciamento tanto no tocante ao espaço quanto à afetividade, além da proximidade cultural e socioeconômica, facilitando a comunicação entre esses sujeitos (ALDETE et al., 2013; BIRHAN; GIDAY; TEKLEHAYMANOT, 2011). Assim, pelo fato de as benzedeiras conviverem e compartilharem das mesmas visões de mundo de seus clientes, cria-se um ambiente que favorece o processo de cura. Acrescenta-se o fato de viverem na própria comunidade e assumirem uma postura de doação em relação ao processo do cuidado, fazendo da sua procura uma alternativa mais atrativa.

Podemos observar em algumas falas que, mesmo após a reza, há preocupação com o bem-estar das crianças. $O$ cuidado não acaba com a volta da criança para casa. Em casos mais graves, elas chegam a "adotar" essas crianças, no sentido de realizar pedidos e preces aos deuses e santos de sua religião, continuamente se tornando ativas na busca pela melhoria do estado patológico. Isso cria um vínculo entre cuidador e cuidando, assim como entre as benzedeiras e os pais. 
Eu rezo todo dia, toda noite eu rezo e quem sai daqui eu já tô rezando pra não haver nada. (B9)

Agente reza... e oferece a aquele santo ou aquela pessoa que já morreu pra que ajude agente.(B4)

Para a benzeção, o tripé mente-corpo-espírito é inseparável, e sua intervenção inclui a cura simultânea desses três elementos. Há, portanto, o que Maciel e Guarim Neto (2006) chamam de "ressignificação do corpo e da alma", dentro do um universo plural, holístico e cósmico. Esses sistemas de cura não se encarregam exclusivamente de tratar doenças orgânicas; também curam doenças que não se encaixam no paradigma biomédico (HERNDON, 2009), doenças que elas julgam ter alguma ligação sobrenatural - e na verdade são estas últimas seu principal foco. Dentre as entrevistadas, todas dizem curar quebrante, elas fazem ligação dessa doença a meios que remetem ao sobrenatural, e pelas entrevistas pode-se notar o número significativo de crianças acometidas por essas doenças.

O quebrante, o uíado e o vento caiado... É gente que bota, quem bota meu filho, quem bota quebrante e uíado bota em tudo que ver e só quem tira é Deus. É a vista mal das pessoas adoece logo ali na hora, vomitando, da febre. Não tem doença que só com a cura resolve na base do mal olhado, quebrante cê tá com espírito má erisipela, tudo isso eu sei curar (B1)

Segundo Luz (2005), na benzeção predomina a terapêutica em relação à diagnose. Mas sabe-se que ambos se conformam de maneira indissociáveis, pois a diagnose ocorre no momento em que a terapêutica está sendo realizada, ao passo que a terapêutica necessita em algum momento da diagnose para ser completada. O cuidado é baseado no sujeito, é nele e a partir dele que o cuidado ocorre. No caso do cuidado a saúde da criança, inclui os pais e demais atores responsáveis pelo bem-estar da criança (LUZ, 2005), não se limitando a uma terapêutica apenas sintomática.

Se for uma dor de que passa em um instante... Mas se for um dor de uma doença grave tem que curar propriamente da doença, tem que o médico passar o tratamento para o médico resolver a doença, para a dor não voltar, agente cura, cura a dor, mais se for uma doença grave só a reza não vai resolver. Tem que a pessoa ir para o dentista, para o médico para saber o problema maior, resolve o problema (doença). Tem que ir para médico descobrir qual é o problema que a pessoa tem. (B6)

Assim, o trabalho é realizado junto ao sujeito e de maneira individualizada. Nas benzeções são utilizadas as rezas básicas e depois, de acordo com a doença, 
realizam-se rezas específicas para aquele "mal”. Segundo elas, há orações que são "enviadas" a elas para uma pessoa em especial. De forma geral, há rezas que são utilizadas para curar qualquer doença, como é o caso do pai-nosso e avemaria, e outras específicas para cada doença, que podem abranger rezas criadas pelos sujeitos responsáveis pelo ritual, rezas aos santos específicos ou mesmo rezas "dadas por Deus".

A reza não é realizada apenas em crianças doentes, apesar de as entrevistadas afirmarem isso. Podemos observar que também podem ser realizadas como forma de proteção.

Em uma criança sadia, pronto, 'o caso de um dia grande, faz a cura naquela criança, sexta feira da paixão, naquelas criancinhas, mesmo que tenha saudável, aí se benze aquelas criança na sexta feira, com vela acesa e água benta, mesmo que a criança esteja saudável, elas vem até aqui, só queria que você vice aqui, começa de 6 horas da manha e vai as 11 da manha, começa novamente de 1 da tarde e vai às 5 da tarde. (B6)

As mulheres, nas suas falas, mostram o conhecimento sobre a importância de aderir a certas práticas de cuidados, e em alguns momentos elas chegam a orientar aos pais sobre práticas saudáveis de alimentação, cuidado com higiene da criança e outros. Este pode se confirmar como importante espaço para uma contribuição mútua entre o saber oficial e popular.

[...] E mesmo assim se a mãe dá amamentação eu peço para dar amamentação enquanto eu tô curando (B8)

Eu dou conselho assim, para ter mais cuidado com os alimentos, com esses mosqueiros, não de banho com água morna em frente ao sol para não dar gripe. (B9)

O seu cuidado é concreto, embora baseado em meios que remetem ao imaterial. É o caso, por exemplo, da cura à distância feita através da foto. Mesmo no caso de fotos, há necessidade de saber o nome e ver a pessoa (por isso a utilização da foto) - "se não, não voga a cura" (B1). A foto é utilizada para pessoas que não acreditam ou que não podem ter um encontro direto com essas profissionais (muitas vezes devido à distância).

Rezo em foto também [...] (B7)

Eu rezei em um menino a prima dela mandou um cartão pedindo a cura, eu pedi o numero, bairro, o lado da casa, e nome do menino depois de cinco dias ela veio me dizer que o menino tava bom. (B13)

Mas são raras as que praticam esse tipo de assistência; a maior parte gosta de estar na presença do indivíduo, pois o procedimento inclui o "olho no olho". O 
corpo parece ser importante no processo - o ver, o sentir, o tocar. Essas parecem

ser importantes variáveis para acompanhar o processo que envolve a doença e o cuidado. É o que diz a pesquisada B5: "Eu só rezo em criança, só rezo em criança. Eu gosto de rezar com a mão na criança, tem que ver a criança e o corpo da criança” (B5). Há um paradoxo nas relaçôes do cuidado praticado pelas benzedeiras: se por um lado a benzeção se estabelece dentro de relações afetivas, que envolvem o ver e o tocar, e a proximidade sociocultural é uma variável importante no estabelecimento do diálogo (BORGES, 2008), a parte ritualística demanda certo distanciamento entre o cuidando e o cuidador, no tocante ao completo entendimento do processo:

Sabe como é? Eu tenho ali uma mão de pilão velhinha. Tem aqui atrás dessa porta, Eu levanto a criança três vezes... (recita uma melodia), só não posso dizer a força da oração, aí eu não poso dizer não. Só não posso explica a força da oração se não pra mim a força da cura já não vale mais. (B5)

Acontece o inverso do que ocorre nas práticas em saúde oficias, em que o distanciamento e a falta de compreensão dos processos são uns dos muitos empecilhos para a terapêutica. Mesmo com a ausência de um diálogo legível, a compreensão do processo ainda permanece, pois o ritual se estabelece dentro do universo simbólico do próprio sujeito e a linguagem oral dá vez a uma linguagem dominada pelo misticismo dos gestos e palavras ininteligíveis. É exatamente na não compreensão que o misticismo entra em seu ápice, contribuindo para o efeito terapêutico esperado e a perpetuação da terapia.

\section{A Reza e o Erudito}

Apesar de terem paradigmas diferentes, a benzeção em alguns momentos se utiliza do sistema oficial de saúde. Ao contrário do que pode parecer a priori, as benzedeiras não têm um comportamento de negação em relação ao profissional erudito. Elas admitem a importância da intervenção desses profissionais no cuidado à saúde da criança, sendo comum indicar um acompanhamento junto a um profissional em saúde, utilizando-o como complemento de sua terapia.

Quando vem e eu vejo que só a cura não resolveu mandou para o hospital. (B2)

Tem vezes que o médico nem dá jeito, só dá jeito reza [...] só a reza às vezes da conta precisa às vezes nem ir para o médico [...] Tem vezes que precisa ir ao médico e tem vezes nem não tem [...] se ficar bom só com minha reza ai nem vai mais. (B4) 
Duas das entrevistadas ressaltam que a reza ainda é o principal contribuinte na obtenção da cura e que, mesmo existindo casos em que a medicina é utilizada, ainda assim não diminuiria a importância da reza. Elucidam inclusive casos em que essas duas modalidades terapêuticas foram usadas de modo paralelo, embora enfatizem a reza como principal contribuinte na obtenção da cura. Assim, mesmo nas doenças que necessitariam de uma intervenção convencional em saúde, elas poderiam atuar. Mesmo não tendo uma sistematização de suas ações, as entrevistadas se comportam de modo semelhante ao que ocorre no sistema oficial em saúde, que inclui a referência, orientação e utilização concomitante de outras terapias não oficializadas. Isso mostra o caráter dinâmico dos processos culturais (CUNHA, 2007).

Em alguns momentos, as benzedeiras se apropriam de instrumentos oficializados dentro da saúde; algumas incorporam a medicina erudita em suas práticas, indicando a utilização concomitante de medicamento. É o caso, por exemplo, elucidado por B7, quando em alguns casos ela orienta a utilização de medicamentos alopáticos:

Às vezes eu passo remédio, remédio que não ofende ninguém, quando ta com infecção intestinal eu mando compra, remédio para inflamação da garganta, soro caseiro para diarreia. (B7)

As doenças delegadas a seus cuidados, apesar de serem vistas como decorrentes do sobrenatural, têm a sintomatologia semelhante a agravos comuns na infância, como é o caso das diarreias de origem helmíntica (TAMER, 2013). Segundo informações colhidas durante a entrevista, as crianças que procuram a reza vêm apresentando quadros de fraqueza, insônia, irritabilidade, sonolência, febre, vômitos, etc.. Mesmo quando a doença não é caracterizada como de origem extrafísica, o benzedor realiza o ritual. Na continuidade da terapia, se não houver melhora no estado inicial da criança eles a encaminham para os profissionais eruditos. As doenças "de médico" seriam caracterizadas como aquelas em que a benzedeira não vê resultado em suas rezas. Segundo essas pessoas, até mesmo os profissionais em saúde já as procuraram para ser benzidos e para que seus filhos também o fossem.

As enfermeiras vêm aqui para me curar, vêm pra me curar elas. (B10)

[...] Até médico para curar eles mesmo, filho e tudo (B1) 
Ai o médico não cura passa o remédio e manda reza, essa semana mesmo eu rezei

um senhor que o médico mandou rezar disse que não tinha remédio para isso não, só a reza. (B9)

Eu rezo no hospital e o médico diz: vá que isso é pra reza. (B13)

Segundo as informantes, nunca esses profissionais oficializaram parcerias. A falta de articulação entre esses sistemas pode em algum momento levar a um distanciamento entre as instâncias formais em saúde e as terapeutas populares. Setton (2002, p. 61) parte da hipótese de que o processo de socialização "[p]ode ser considerado um campo estruturado pelas relações dinâmicas entre instituições e agentes sociais [...] a relação de interdependência [...] é uma forma de afirmar que as relaçôes estabelecidas entre eles podem ser de aliados ou de adversários". Pensar em benzeção como uma forma na qual não há uma efetiva socialização é negá-la enquanto uma expressão social em saúde.

A benzeção não está apenas ligada à medicina; parece quase impossível falar em benzeção sem remeter aos chamados "remédios caseiros" (GÜNEWALD, 2002). Na presença de sintomas como cólicas e febre, são os momentos em que mais se indica a utilização dos métodos fitoterápicos. Há, portanto, uma indiscutível ligação entre benzeção e fitoterapia. Seu uso parece estar presente no dia a dia das pessoas que procuram a cura pela reza e, se formos analisar, elas seguem a mesma lógica. Segundo Nery (2006), é impossível separar a planta medicinal do rito mágico-religioso. Oliveira (1985) reforça essa ligação quando afirma que essas profissionais são vistas pela comunidade como verdadeiras cientistas populares, misturando o mundo místico e os conhecimentos curativos das plantas.

\footnotetext{
Quando eu vejo que merece um chá para dor de cólica, para febre, eu ensino também, às vezes as crianças tem bronquite com anemia, na dentição, ai eu vejo que as crianças estão precisando de um medicamento para anemia, tá precisando de um remédio forte para expectorar, e eu faço também remédio caseiro, tem o remédio da criança e do adulto, só que quando vem com uma febre e eu não posso curar eu mando para o hospital [...]. (B2)
}

Durante a entrevista, observa-se que esse trabalho está correndo sério risco de extinção, pois muitas delas estão em idade muito avançada e não se encontram mais "novas" benzedeiras. Borges, Shimizu e Pinho (2009) alertam para a notável queda no número de terapeutas, o que dificulta a perpetuação dessa tradição. A nova geração, apesar de acreditar no poder da reza, não quer 
"aprendê-la”. A crescente diminuição se dá pela pouca aderência da população jovem ao "aprendizado", podendo ser explicada pelo que o autor chamaria de o "esfriamento da fé" e desinteresse pelo mágico e sagrado, advindo com a secularização e a modernidade: "Não tem gente que num quer não, esse povo novo num querem rezar não, aprenderem a rezar, não" (B2).

É importante que esses atores sociais em saúde continuem a expressar essa terapia de cura. Esta é, acima de tudo, a maneira como esses grupos sociais, muitas vezes marginalizados e oprimidos pelo sistema de saúde convencional, lutam pela sobrevivência e pela aquisição de uma melhor qualidade de vida.

\section{Considerações finais}

As benzedeiras do município de Caraúbas seguem um perfil muito semelhante no tocante às crenças e à utilização do ritual de cura. As frases refletem uma percepção do processo saúde próprias dessa cultura, misturando conhecimentos que remetem ao empírico e ao científico. A crença no método é algo muito presente, sendo referida durante toda a pesquisa, que ganha força com a utilização do ritual e os processos afetivos construídos ao longo do cuidar.

Essa crença não é pormenorizada quando se reconhece a importância do uso concomitante da medicina. Essas mulheres, em suas falas, se mostram dispostas a contribuir com o sistema, em um processo que infelizmente ainda permanece muito unilateral, mas com a disposição em articular arte e ciência, visualizada pelo encaminhamento e reconhecimento da importância do sistema oficial em saúde. Isso se configura como um espaço para a Estratégia Saúde da Família realizar parcerias que incentivem o uso concomitante entre essas modalidades terapêuticas e o sistema oficial, contribuindo assim para melhorar a assistência. Pesquisas como a de Muula (2009), Audet et al. (2013) e Tamer (2013) mostram a importância e a viabilidade de realizar tal parceria.

Devemos sobretudo pesquisar e aproveitar os pontos em comum para possibilitar uma articulação entre os saberes a partir de uma lógica que não seja pautada apenas no conhecimento hegemônico. Fazer isso é um trabalho político, é praticar cidadania. Procurar recuperar essa tradição terapêutica é acima de tudo resgatar as origens socioculturais brasileiras, pois esta se configura como um saber criado a partir da miscigenação de diversas culturas presentes no Brasil, traduzindo assim nossa historicidade. ${ }^{1}$ 


\section{Referências}

ARCHANJO, L.R.D.; LEITE, A.T. A benzeção como prática terapêutica. Rev. RUBS, Curitiba, v.1, n.3, p.15-19, set./dez. 2008. Disponível em: < rubs.up.edu.br/.../Artigo\%20 -\%20A\%20benzeção\%20como\%20prática\%20 Terapûtica.pdf > Acesso em: 16 ago. 2009.

AUDET C.M. et al. Educational Intervention Increased Referrals to Allopathic Care by Traditional Healers in Three High HIV-Prevalence Rural Districts in Mozambique. Rev. PLoS ONE. 2013. Disponível em <http://www.ncbi.nlm.nih.gov/pmc/articles/ PMC3731350/> Acesso em: 21 nov 2013.

BIRHAN, W.; GIDAY, M. The contribution of traditional healers' clinics to public health care system in Addis Abeba, Ehthiopia: a cross-sectional study. Rev. J Ethnobiol Ethnomed. v. 7, n. 39, Dec 2011. Disponível em: <http://www.ncbi.nlm.nih.gov/pmc/articles/ PMC3247023/>. Acesso em: 21 nov 2013.

BORGES, M.; SHIMIZU, H.; PINHO, D. Representaçôes sociais de parteiras e benzedeiras sobre o cuidado. Rev. Ciência, Cuidado e Saúde. Rio de Janeiro, 8 set. 2009. Disponível em: <http://periodicos.uem.br/ojs/index.php/CiencCuidSaude/article/view/8207/4599>. Acesso em: 11 abr. 2010.

BORGES, M.S. Incorporação do saber de parteiras e benzedeiras às práticas de saúde. Rev. Com. Ciências Saúde. v. 19,. p. 323-332, abr 2008. Disponível em: <www.fepecs.edu.br/ revista/Vol19_4art05.pd>Acesso em: 12 mar. 2010.

CUNHA, M.A. de A. O conceito "capital cultural” em Pierre Bourdieu e a herança etnográfica. Rev. Perspectiva, Florianópolis, v. 25, n. 2, 503-524, jul./dez. 2007. Disponível em: <www.perspectiva.ufsc.br/.../09_Demanda_Continua_MariaAmalia.pdf > Acesso em: 29 mar. 2009.

FARAG, T.H. et al. Seeking Care for Pediatric Diarrheal Illness from Traditional Healers in Bamako, Mali. Rev. The American of Tropical Medicine and Hygiene. v. 81, supl. 1, p. 2128, July 2013. Disponível em: http://www.ncbi.nlm.nih.gov/pmc/articles/PMC3748497. Acesso em: 21 nov 2013.

GÜNEWALD, R. de A. A Jurema no regime de índio: o caso Atikum. In: MOTA, C.N. da; ALBUQUERQUE, U.P. (Org.). As muitas faces da Jurema: da espécie botânica à divindade afroindígena, Recife: Bagaço, 2002.

HAVERKORT, B.; MILLAR, D. Constructing diversity: the active role of rural people in maintaining and enhancing biodiversity. Etnoecológica, v. 2, n. 3, p. 51-64, 1994.

HEMDON, C.N. et al. Disease concepts and treatment by tribal healers of an Amazonian floret culture. Rev. J Ethnobiol Ethnomed. v. 5, n. 27, Oct 2009. Disponível em <http:// www.ncbi.nlm.nih.gov/pmc/articles/PMC2774292> Acesso em: 21 nov 2013.

LEVI-STRAUSS, C. O feiticeiro e sua magia. In: Antropologia Estrutural. 4 ed.

Rio de Janeiro: Tempo Brasileiro, 1991. p. 193-214. 
LUZ, M.T. Cultura contemporânea e medicinas alternativas: novos paradigmas em saúde no fim do século XX. Physis: revista de saúde coletiva [online]. Rio de Janeiro, v. 15, supl., p. 145176, 2005. Disponível em: <www.scielo.br/pdf/physis/v7n1/02.pdf> Acesso em: 29 abr 2008. MACIEL, M.R.A.; GUARIM NETO, G. Um olhar sobre as benzedeiras de Juruena (Mato Grosso, Brasil) e as plantas usadas para benzer e curar. Bol. Mus. Para. Emílio Goeldi. Ciênc. hum.[online]. v. 1, n. 3, p. 61-77, 2006. Disponível em <http://www.scielo.br/scielo. php?script=sci_arttext\&pid $=$ S1981-81222006000300003\&lng=pt\&nrm=iso $>$ Acesso em: 21 nov 2013.

MINAYO, M.C. de S. O desafio do conhecimento: pesquisa qualitativa em saúde. 7. ed. São Paulo: Hucitec, 269 p, 2000.

MUULA, A.S. et al. Association between maternal use of traditional healer services and child vaccination coverage in Pont-Sonde, Haiti. Rev. Int. J. Equity Health, v. 8, n. 1, 2009. Disponível em <http://www.ncbi.nlm.nih.gov/pmc/articles/PMC2651879> Acesso em: 21 nov 2013.

NERY, V.C.A. Rezas, Crenças, Simpatias e Benzeçôes: costumes e tradições do ritual de cura pela fé. In: Congresso Brasileiro de Ciências da Comunicação, 29., 2006, Brasília. Anais. São Paulo: Intercom, 2006. CD-ROM Disponível em: < http://galaxy.intercom.org. br:8180/dspace/handle/1904/1228 > Acesso em: 25 out. 2010.

OLIVEIRA, E. R. O que é benzeção. São Paulo: Brasiliense, 1985.

PASA, M.C. A utilização dos recursos vegetais no Vale do Aricá, Mato Grosso: um estudo etnoecológico. Dissertação (Mestrado em Ecologia e Conservação da Biodiversidade) Instituto de Biociências. Universidade Federal de Mato Grosso, Cuiabá, 1999.

SETTON, M. da G.J. A teoria do habitus em Pierre Bourdieu: uma leitura contemporânea. Revista Brasileira de Educação, maio-ago, n. 20, p. 60-70, 2002. Disponível em: <www.anped. org.br/rbe/.../rbde20_06_maria_da_graca_jacintho_setton.pdf> Acesso em: 19 fev. 2010.

TESSER, C.D. Medicalização social (II): limites biomédicos e propostas para a clínica na atenção básica. Rev. Interface [online]. Botucatu, v. 10, n. 20, p. 347-362, 2006. Disponível em <http://www.scielo.br/scielo.php?script=sci_arttext\&pid=S1414$32832006000200006 \& \operatorname{lng}=$ pt\&nrm=iso $>$ Acesso em: 21 nov 2013.

\section{Nota}

${ }^{1}$ R.E.G. de Medeiros participou da concepção, pesquisa, metodologia, elaboração do texto e na redação final. E.G.C. do Nascimento participou da concepção, metodologia, redação final e revisão crítica. G.M.D. Diniz participou da elaboração do texto, redação final e revisão crítica. J.C. Alquieri participou da elaboração do texto, redação final e revisão crítica. 
The complexity inside the simplicity of the care: the role of a healer in child healthcare.

Speaking about culture and health issues is also speaking of matters of religion and spirituality, therapies that were not yet made official and cross the mysticism of these issues. Moreover, despite lacking the technical-scientific proof demanded by the current hegemonic model in healthcare, they are knowledge kept alive throughout the history of mankind and perpetuate until the present day. The study aimed to analyze the perceptions of traditional healers about the child healthcare in the city of Caraúbas$\mathrm{RN}$, Brazil, focusing on the practice of blessing. It was a qualitative and exploratory study, conducted through semi-structured interviews and with a sample of 16 traditional healers who live in the urban area of the city. It was clear that the care delivered is based on aspects that involve affection, and it was noticeable that the healers are very similar among themselves when regard their rituals. The healers show that they are willing to put together art and science, since their acceptance of the importance of the official healthcare system. This set up a place for the Family Health Strategy to create partnerships that promote the concomitant use of this therapeutic modality and the official system, thereby contributing to the improvement of the care itself.

Key words: medical anthropology; health; ethnology. 